Kinder und Jugendliche in der COVID-19-Pandemie 



\section{Kinder und \\ Jugendliche in der COVID-19-Pandemie}

Perspektiven aus Praxis und Wissenschaft

Herausgegeben von

Anne Oommen-Halbach, Simone Weyers und Maria Griemmert

\section{$\mathbf{d}|\mathbf{u}| \mathbf{p}$}

düsseldorf university press 
Diese Publikation wurde finanziell unterstützt durch das Jugendamt der Landeshauptstadt Düsseldorf.

ISBN 978-3-11-075953-2

e-ISBN (PDF) 978-3-11-076036-1

e-ISBN (EPUB) 978-3-11-076041-5

DOI https://doi.org/10.1515/9783110760361

\section{(cc) BY-NC-ND}

Dieses Werk ist lizenziert unter der Creative Commons Namensnennung - Nicht kommerziell Keine Bearbeitung 4.0 International Lizenz. Weitere Informationen finden Sie unter http:// creativecommons.org/licenses/by-nc-nd/4.0/.

\section{Library of Congress Control Number: 2021949858}

\section{Bibliografische Information der Deutschen Nationalbibliothek}

Die Deutsche Nationalbibliothek verzeichnet diese Publikation in der Deutschen Nationalbibliografie; detaillierte bibliografische Daten sind im Internet über http://dnb.dnb.de abrufbar.

(C) 2022 bei den Autoren, Zusammenstellung (C 2022 Anne Oommen-Halbach, Simone Weyers und Maria Griemmert, Walter de Gruyter GmbH, Berlin/Boston Dieses Buch ist als Open-Access-Publikation verfügbar über www.degruyter.com. $\mathrm{d}|\mathrm{u}| \mathrm{p}$ düsseldorf university press ist ein Imprint der Walter de Gruyter GmbH

Umschlaggestaltung: ( freshidea - stock.adobe.com

Satz: le-tex publishing services $\mathrm{GmbH}$, Leipzig

Druck und Bindung: $\mathrm{CPI}$ books $\mathrm{GmbH}$, Leck

dup.degruyter.com 